https://doi.org/10.3126/pragya.v7i1.35107

\title{
Provincial Poverty in Nepal
}

Gyanwali Gokarna Prasad, PhD

\begin{abstract}
Poverty is not only the severe economic condition of people but it is also the cultural, ethical, social, political, psychological and economic imperative of mankind. It is one of the distressing circumstancesof people in developing countries have to contend with in their daily lives. It is common among the low and middle income class in these countries like Nepal.This research is based on the multidimensional poverty index (MPI) such as those related to education, health, material wellbeing, energy, water and sanitation, structure of house, and access to other services, varies considerably in seven provinces of Nepal. It illustrates the importance of location-specific data in the development of effective poverty reduction strategies of federal and provincial governments.The MPI shows that, the 28.6\% of the people of Nepal are still multi-dimensionally poor meaning that their lives are battered by several deprivations simultaneously. This paper also discusses about the trends and measurement of poverty in Nepal as well as the provincial socio-economic conditions and distribution of poverty.
\end{abstract}

Key words: Multidimensionality, deprivations, eradication, headcount, Capability.

\section{Introduction}

Poverty means lack of property, lowstandard of living and measurable conditions of the all spheres of life. It is about not having enough money to meet basic needs including food, clothing and shelter. However, poverty is much more than that. According to World Bank (2018), Poverty is hunger, lack of shelter, is being sick and not being able to see a doctor. It is not having access to school and not knowing how to read. It is also not having a job, is fear for the future, living one day at a time. It means poverty has various dimensions and cannot define by one or two variables. It has many faces, changing from place to place and across time, and has been described in many ways. Most often, poverty is a situation people want to escape. So, poverty is a call to action - for the poor and the wealthy alike - a call to change the world so that many more may have enough to eat, adequate shelter, access to education and health, protection from violence, and a voice in what happens in their communities (WB, 2018). Eric Jenson defines poverty is not only the lack of economic resources but it is the factors which affects all parts of our life. According to him, poverty 
as a chronic and debilitating condition that results from multiple adverse synergistic risk factors and affects the mind, body, and soul (Jenson, 2009).

Poverty has multi-facets, from small things of human life to the psychological, socialcultural as well as economic conditions. In addition to a lack of money, poverty is about not being able to participate in recreational activities; not being able to send children on a day trip with their schoolmates or to a birthday party; not being able to pay for medications for an illness. Anthropologist Lewis (1961) mentioned that it is because of the culture of poverty but Gorski (2008) rejects this concept and mentioned that, there is no such thing as a culture of poverty. Differences in values and behaviors among poor people are just as great as those between poor and wealthy people.These are all costs of being poor. Those people who are barely able to pay for food and shelter simply can't consider these other expenses. When people are excluded within a society, when they are not well educated and when they have a higher incidence of illness, there are negative consequences for society. We all pay the price for poverty. The increased cost on the health system, the justice system and other systems that provide supports to those living in poverty has an impact on our economy (GNB, 2019). The United Nations (2018), has defined poverty either in relative or absolute terms. So, it has multiple factors, either physical to mental or material conditions to non-materials of life processes.

\section{Objectives}

The overall objective of this article is to find out the situation of poverty in the provincial level of Nepal. The specific objective is to analyze the overall economic conditions of provinces, comparative study of level of poverty and its impacts to socio-economic conditions and other sectors of human life.

\section{Methods and data source}

Regarding the objectives, the analytical and descriptive methods are applied in this study. The data used in the study is quantitative which are collected from the economic survey of the ministry of finance, World Bank, OECD, CBS Living standard surveys, MPI report of WB, various articles, journals, news papers and reports of International organizations as well as national organizations.

\section{Poverty and its Types}

One of the most debatable issues of the century is the poverty which has various forms. According to UNICEF (2012), Poverty is when there is no wheat at home, when there is little food, when Mom and Dad have no jobs, when there are no utensils, good clothes, and sometimes - when there is no home. And even if there is, it has dirty walls, no carpets and 
blankets. Poverty is when a person is often hungry.Individual thinkers to international organizations have categorized the poverty on the basis of various components like social poverty, educational poverty, health poverty, spiritual poverty, environmental poverty, and economic poverty. The UNDP (1998) has provided six different types of poverty such as human poverty, income poverty, extreme poverty, overall poverty, relative poverty, and absolute poverty. World Bank defines two types of poverty :Extreme poverty as living on less than US\$1.25 per day and boost shared prosperity, defined as promoting the growth of per capita real income of the poorest $40 \%$ of the population in each country (WB, 2016). Conceptualizing poverty as a one dimensional shortfall, in terms of income, consumption or expenditure raises many has methodological issues and forms.Similarly, Jenson (2009) identifies six types of poverty i.e. situational poverty, generational poverty, absolute poverty, relative poverty, urban poverty and rural poverty. Not only these, there are other different forms of poverty defined by world prominent scholars as well as international organizations. Sen (1999), defined it on the basis of human capability. According to him, capability notion postulates that poverty results from a lack of capability to 'function' or to 'achieve' well-being, where well-being is defined as the "ends" and capability as the "means" to achieve it. The recent developments emphasize capability and social exclusion or social inclusion, to be more positive as alternative and more promising approaches to poverty analysis (Nikku \& Azman, 2014).

\section{Poverty in Nepal}

The development plan was started in 1956 A.D. in the context of Nepal. Most of the plans had poverty alleviation as the main objective but they are not as fruitful as expected by the government authorities.Following the restoration of democracy in 1990, poverty reduction was one of the main objectives of the Eight (1992-1997) and Ninth Periodic Plan (19972002). Looking at the widespread poverty in the nation, the Tenth Periodic Plan, (20022007) to fifteenth five year plan (2019-24) has clearly mentioned that poverty alleviation is the single objective of the nation (Chaudhary, 2018). Latest two development plans, $14^{\text {th }}$ three year and $15^{\text {th }}$ five year plans also concentrated their programs to reduce the poverty from the country. The objective of the 14th periodic plan, (2017-19) was to facilitate socioeconomic transformation and poverty reduction through high economic growth, with productive employment and equitable distribution of resources. Similarly, the concept paper presented by National Planning Commission (2015)has set a target of reducing absolute poverty from the current level of 18.7 per cent to 13 per cent by the end of the 15th periodic plan. Likewise, it aims at reducing the percentage of people reeling under multi-dimensional poverty from 28.6 per cent to 14 per cent. Regarding per capita income, it is aimed at achieving USD 1,600 per capita income by the end of the 15th periodic plan and a 
whopping USD 12,100 in 25 years from now. These objectives are highly ambitious and require constant and concerted efforts from the government, private sector and other stakeholders (Maharjan, 2019 and NPC, 2019). These facts shows that the development plans of Nepal from its initial period to now has been prioritized their objectives to reduce the poverty but outcome of these plans was not satisfactory and seems as the vicious cycle of poverty.

\section{Measurement of Poverty in Nepal}

The measurement of poverty is a very complex process. According to Institute for Research in Poverty (IRP, 2020), there are two types of poverty measurement processes : official poverty measure (income, threshold, and family)and the Supplemental Poverty Measure (Resource units and unrelated individuals, Based on expenditures of food, clothing, shelter, and utilities, Vary by family size and composition, as well as geographic adjustments for differences in housing costs by tenure, Five-year moving average of expenditures on FCSU and Sum of cash income, plus noncash benefits that resource units can use to meet their FCSU needs, minus taxes (or plus tax credits), minus work expenses, medical expenses, and child support paid to another household) (Fox, 2017). Recently at 2019, World Bank developed new method to measure poverty which is known as multidimensional poverty index (MPI). It reflects both the incidence of multidimensional deprivation (a headcount of those in multidimensional poverty) and its intensity (the average deprivation score experienced by poor people). The National Planning Commission has using MPI for the measurement of poverty in Nepal since 2011.

Nepal has been practiced different methods to measure poverty in 1976/77 (NPC), 1984/85 (NRB), and 1989 (WB/UNDP). Living Standard Survey was the very systematic approach which has been conducted for three times in Nepal, of which first was in FY 1995/96, second in FY 2004/05 and third in FY 2009/10. In order to estimate poverty, Nepal Living Standard Survey, 1995/96 has reduced the calorie requirement per capita per day to 2124 as compared to earlier surveys in which that requirement was 2250 as shown in Table no.2. Therefore, poverty estimation of NLSS seems to be non-comparable to other surveys. If calorie requirement of NLSS is adjusted according to earlier surveys, incidence of poverty in Nepal will increase. 
Table No.1: Poverty measurement in Nepal

\begin{tabular}{|l|l|l|l|l|l|}
\hline Source & Year & $\begin{array}{l}\text { Sample } \\
\text { HH }\end{array}$ & $\begin{array}{l}\text { Calorie } \\
\text { Requirement/ Day }\end{array}$ & $\begin{array}{l}\text { Poverty Line/ } \\
\text { Person/Rupees }\end{array}$ & $\begin{array}{l}\text { Incidence of } \\
\text { poverty }\end{array}$ \\
\hline NPC & $1976 / 77$ & & 2256 & & 36.2 \\
\hline MPHBS/NRB & $1984 / 85$ & & 2250 & & 42.5 \\
\hline WB/UNDP & 1989 & & 2250 & & 40.0 \\
\hline NLSS l/CBS & $1995 / 96$ & 3912 & 2124 & 5089 & 41.8 \\
\hline NLSS lI/CBS & $2003 / 04$ & 3373 & 2144 & 7696 & 30.8 \\
\hline NLSS lII/CBS & 2011 & 7200 & 2220 & 19,261 & 25.2 \\
\hline
\end{tabular}

Source: World Bank, NPC, CBS

Table no.1, shows that the number of sample household, required calorie and income level in NLSS I, NLSS II and NLSS III has been different. The number of sample households also has been decreased from NLSS I to NLSS II and increased to NLSS III. This could have affected the estimation of poverty incidence. The poverty rate is a political issue in Nepal because of the multiform data of the government and international organizations like WB, UNDP, ADB etc. They wanted to show the minimum rate of poverty because of their own effort.The official poverty rate is equally sketchy - hovering from $18.7 \%$ to $40 \%$. A household survey conducted for identifying poor households in 26 districts in 2070 BS suggests $40 \%$ population lives below the poverty line. However, a Multi-Dimensional Poverty Index (MPI) measurement done in 2016 - with a special focus on health, education and living standard - shows the percentage of those living below the poverty line at $28.6 \%$ percent while the government's 15th periodic development plan document further scaled it down to $18.7 \%$, on the basis of consumption and income parameters. There are $34 \%$ of the population are multi-dimensionally poor while an additional $22.3 \%$ are classified as vulnerable to multidimensional poverty (NPC, 2018). Similarly, MPI (2016) mentioned that, the breadth of deprivation in Nepal, which is the average deprivation score experienced by people in multidimensional poverty, is 43.6 percent. The MPI, which is the share of the population that is multi-dimensionally poor, adjusted by the intensity of the deprivations, is 0.148. The multidimensional poverty headcount is 19.0 percentage points higher than income poverty. This implies that individuals living above the income poverty line may still suffer deprivations in health, education and/or standard of living (MPI, 2016). The other indicators of poverty are given in the table no.2. 
Table No.2: Poverty Indicators in Nepal

\begin{tabular}{|l|l|l|}
\hline S.N & Factors & Value \\
\hline 1 & MPI value & 0.148 \\
\hline 2 & Head count (\%) & 34.0 \\
\hline 3 & Intensity of deprivations (\%) & 43.6 \\
\hline 4 & Population share of Vulnerable to multidimensional poverty (\%) & 22.3 \\
\hline 5 & Population share in severe multidimensional poverty (\%) & 11.6 \\
\hline 6 & Population share Below income poverty line (\%) & 15.0 \\
\hline 7 & Contribution to overall poverty of deprivations in (\%) & • 31.5 \\
& $\bullet \quad$ Health & $\bullet 27.2$ \\
& $\bullet \quad$ Education & $\bullet 1.3$ \\
\hline
\end{tabular}

Source : HDR, 2019

But the official and authentic figure of poverty is $25.2 \%$, according to Nepal Living Standard Survey III(2011), which consists of a rigorous method of calculating the Households (HHs) level consumption on the basis of cost of basic needs (CBN methodology). The Central Bureau of Statistics (CBS) is conducting the NLSS IV this year and the result is expected to come within the next 15 months, according to officials.A senior government official, who prefers not to be named, questioned the current poverty rate of $18.7 \%$ mentioned in the 15th development plan document. According to him, it is unscientific and unethical to claim that the poverty rate is 18.7 percent. He further added that, poverty estimation cannot be taken on a linear fashion and through a regression analysis of poverty headcount on GDP, especially when the distance between the surveys is 10 years. There are many other factors that contribute to fluctuations in poverty rate (Subedi, 2019). It indicates that, the government officials , bureaucrats, member of NPC as well as specialists of this subject have no common consensus about the factual data of poverty in Nepal.

\section{Federal Structure: Socio-Demographic \& Economic Situation}

There are 7 provinces and 753 local levels along with a federal government in the federal system of Nepal. In local level, there are 6 Metropolitan cities, 11 Sub- Metropolitan cities, 276 Municipalities and 460 Rural Municipalities. As per the available statistics, there is unevenness in development of economic and social sectors among the provinces.Out of 753 local levels, Province No. 1 consists of highest number of local levels i.e., 137 where as Karnali Province comprises 79 local levels, the lowest among all. Out of 6 Metropolitan cities, Province No. 3 comprises 3 Metropolitan cities and Province No. 1, Province No. 2 
and Province No. 4 have one Metropolitan city each. Likewise, out of 11 Sub-metropolitan cities, Province No. 5 comprises 4 Sub-metropolitan cities, the highest number where as Province No. 4 and Karnali Province do not have any Sub-metropolitan city. Based on the National Population Census, 2068, 20.9 percent population, the largest share of population, belongs to Province No. 3 where as Karnali Province consists of smallest share of population i.e., 5.9 percent (CBS, 2011). Some of the socio-demographic situations of provinces is given in table no.3.

Table No.3: Provincial Socio-demographic situations

\begin{tabular}{|l|l|l|l|l|l|l|l|l|}
\hline Indicators & Nepal & $\begin{array}{l}\text { Province } \\
\mathbf{1}\end{array}$ & $\begin{array}{l}\text { Province } \\
\mathbf{2}\end{array}$ & $\mathbf{B a g m a t i}$ & Gandaki & $\begin{array}{l}\text { Province } \\
\mathbf{5}\end{array}$ & Karnali & Sudurpachhim \\
\hline $\begin{array}{l}\text { No. of local } \\
\text { level }\end{array}$ & 753 & 137 & 136 & 119 & 85 & 109 & 79 & 88 \\
\hline Population (\%) & 100 & 17.1 & 20.4 & 20.9 & 9.1 & 17 & 5.9 & 9.6 \\
\hline $\begin{array}{l}\text { Density per } \\
\text { sq.km. }\end{array}$ & 175 & 559 & 272 & 112 & 202 & 56 & 131 \\
\hline Area (\%) & & 17.6 & 6.6 & 13.8 & 15.3 & 11.8 & 21.6 & 13.3 \\
\hline $\begin{array}{l}\text { Unemployment } \\
\text { (No. in } \\
\text { thousand) }\end{array}$ & 908 & 136 & 317 & 161 & 60 & 144 & 130 & 59 \\
\hline $\begin{array}{l}\text { Life expectancy } \\
\text { (Living born) }\end{array}$ & 69.7 & 70.7 & 67.8 & 70.7 & 71.7 & 69.3 & 66.8 & 68.6 \\
\hline
\end{tabular}

Source : Economic survey, 2018/19/20

The system of measuring GDP by provincewise has commenced from the 2018/19 onwards. As Nepal's Government has introduced the concept of equitable and balanced development through its first budget of full implementation of federalism in last year, the model has shown positive impact on provincial economic growth. Out of the total GDP of Nepal Rs.3464.31 billion, contributionof Province no. 3 is estimated to stand the highest with 41.4 percent, and that of KarnaliProvince is estimated to stand at the lowest with 3.4 percent in 2018/19.

In 2019, Nepal has 6.8 percent growthrate of GDP of the country, where as province No. 5 is estimated to have the highest growth rate with 7.4 percent and Karnali Province is estimated to have the lowest growth rate 5.7 percent. Sucheconomic growth rate of Province no. 1, Province no. 2 and Far Western is almost identical. Similarly, Karnali province has least contribution and Bagmati has highest contribution in GDP. It indicates that, there is the vast difference of growth rate, GDP and other indicators in the provincial level of Nepal. 


\section{Poverty in Provincial level}

Monetary poverty in Nepal has been predominantlyrural. In 2010, the urban poverty rate was $15.5 \%$, significantly lower than the rural poverty rate of $27.4 \%$ with notable regional disparities. There is aregional disparity in poverty incidence, with the Midwesternand Far Western regions of the country beingpoorer than the rest of the country. Recalculation ofmonetary poverty across provinces under the newfederal structure shows levels of poverty incidenceranging from $17 \%$ to $46 \%$. Ranking of provincesby poverty incidence is difficult due to overlappingconfidence intervals.

Table no.4 : Provincial Level of Poverty

\begin{tabular}{|l|l|l|l|l|l|l|l|l|}
\hline Indicators & Nepal & $\begin{array}{c}\text { Province } \\
\mathbf{1}\end{array}$ & $\begin{array}{c}\text { Province } \\
\mathbf{2}\end{array}$ & Bagmati & Gandaki & $\begin{array}{c}\text { Province } \\
\mathbf{5}\end{array}$ & Karnali & $\begin{array}{l}\text { Sudurp } \\
\text { achhim }\end{array}$ \\
\hline $\begin{array}{l}\text { Population under } \\
\text { absolute poverty (\%) }\end{array}$ & 18.7 & 12.4 & 19.8 & 15.3 & 15.5 & 18.2 & 28.9 & 33.9 \\
\hline $\begin{array}{l}\text { Multidimension } \\
\text { alpoverty rate }\end{array}$ & 28.6 & 19.7 & 47.9 & 12.2 & 14.2 & 29.9 & 51.2 & 33.6 \\
\hline $\begin{array}{l}\text { Property based } \\
\text { Gini multiplier }\end{array}$ & 0.3 & 0.4 & 0.2 & 0.3 & 0.4 & 0.3 & 0.4 & 0.3 \\
\hline $\begin{array}{l}\text { Unemployment } \\
\text { rate (\%) }\end{array}$ & 11.4 & 10.2 & 20.1 & 7.0 & 9.0 & 11.2 & 9.7 & 11.5 \\
\hline
\end{tabular}

Source : Economic survey, 2018/19

The multidimensional poverty rate in Province No. 1, Province No. 3 and Province No. 4 is below than the national average, whereas it is above the national average in other provinces. The multidimensional poverty rate is highest in Karnali Province and the lowest in Province No. 3. Although, there was large speculation to condense the poverty since the Panchayat period but the result was so insignificant and no changes in the life of people.

\section{Provincial MPI}

Nepal's national MPI utilizes the global MPI's dimensions,indicators, and cutoffs , because these reflect its priorities as expressed in Nepal's strategy to meet the Sustainable Development Goals (SDGs), Nepal's Constitution, the 14th National Development Plan (2017-2019), and can be implementedusing the 2014 MICS dataset(MPI, 2018). It has uses ten indicators to calculate the poverty which are: Nutrition, Child mortality, Years of schooling, School attendance, Sanitation, Water, Electricity, Cooking fuel, Flooring and roofing and Assets. MPI depicts the data where poor people live, across the seven provinces. This is important because, as the province briefings mention, some of the provinces with lower levels of poverty nonetheless house many more poor people than the poorest 
provinces. Province 2 houses the largest number of multi- dimensionally poor followed by Province 5. Province 4 has the lowest number of poor people.

Table no.6: Severe \& Vulnerable Poverty of the Provinces

\begin{tabular}{|l|l|l|l|l|}
\hline S.N. & Provinces & Severe poverty & Vulnerable poverty & Poverty Rate (\%) \\
\hline 1 & Province no.1 & 17.4 & 29.5 & 12 \\
\hline 2 & Province no.2 & 20.8 & 21.5 & 35 \\
\hline 3 & Bagmati & 4.7 & 20.5 & 9 \\
\hline 4 & Gandaki & 5.6 & 22.1 & 5 \\
\hline 5 & Province no.5 & 8.2 & 20.1 & 20 \\
\hline 6 & Karnali & 10.3 & 20.6 & 8 \\
\hline 7 & Sudurpachhim & 6.6 & 25.9 & 11 \\
\hline
\end{tabular}

Source: MPI, 2018.

Above table shows that, severe poverty rate highest in province no 2 and lowest in Bagmati and vulnerable poverty is highest in province no .1 and lowest in province no.5. According to MPI (2018), Bagmati Province has the lowest MPI value at 0.051 and Karnali Province has the highest MPI of all provinces in Nepal, at 0.230 .The headcount ratio of multidimensional poverty is highest in Karnali is $51.2 \%$, meaning that morethan half of the population of the province is multi - dimensionally poor and lowest in Bagmati is 12.24\%.

Table no.7: Provincial value of $\mathrm{H}$ and $\mathrm{A}$.

\begin{tabular}{|l|l|l|l|}
\hline Provinces & MPI & Head Count Ratio (\%) - H & Intensity (\%) - A \\
\hline Provinces 1 & 0.085 & 19.67 & 43.22 \\
\hline Provinces 2 & 0.217 & 47.89 & 45.32 \\
\hline Bagmati & 0.051 & 12.24 & 41.86 \\
\hline Gandaki & 0.061 & 14.19 & 42.88 \\
\hline Provinces 5 & 0.133 & 29.92 & 44.33 \\
\hline Karnali & 0.230 & 51.22 & 44.88 \\
\hline Sudurpachhim & 0.146 & 33.56 & 43.51 \\
\hline National & 0.127 & 28.62 & 44.23 \\
\hline
\end{tabular}

Source: MPI, 2018

Similarly, the intensityof poverty in Province 2 is $45.3 \%$, which means that those who are identified as multi - dimensionally poor and deprived, where as Bagmati has lowest $41.86 \%$ intensity of poverty in comparison to other provinces of Nepal. The value of head count ratio and intensity of poverty is given in table 7.

MPI has uses ten indicators to measure the multidimensional poverty for provincial level. MPI data shows that, the largest censoredheadcount ratio is found in the cooking 
fuelindicator (28.2\%). About $27 \%$ of the population aremulti - dimensionallypoor and do not have adequateflooring and roofing material. Furthermore, about19\% are both multi dimensionally poor and sufferfrom inadequate sanitation. Because the educationand health indicators carry higher weights than living standard indicators, the deprivationsin nutrition and years of schooling are alsoparticularly important.

Table no.8: Poverty indicators

\begin{tabular}{|l|l|l|l|l|l|l|l|}
\hline Indicators & Pro.1 & Pro.2 & Bagmati & Gandaki & Pro.5 & Karnali & $\begin{array}{l}\text { Sudurpac } \\
\text { hhim }\end{array}$ \\
\hline Nutrition & 13 & 17.4 & 11.8 & 18.1 & 16 & 15.1 & 16.1 \\
\hline Child mortality & 12.9 & 7.8 & 12 & 11 & 16.4 & 16 & 15.8 \\
\hline Years of schooling & 21.3 & 20 & 24.8 & 21 & 15.8 & 12.4 & 10.6 \\
\hline School attendance & 7.8 & 14.1 & 3.3 & 3.8 & 8 & 5.5 & 9.0 \\
\hline Cooking fuel & 12.6 & 12.2 & 12.7 & 12.5 & 12.8 & 12.3 & 12.7 \\
\hline Sanitation & 9.2 & 11.0 & & 4.1 & 10 & 3.4 & 5.5 \\
\hline Water & 1.6 & 0.4 & 4.3 & 3.2 & 1.8 & 6.4 & 4.1 \\
\hline Electricity & 3.8 & 3.4 & 3.6 & & 4.6 & & 4.4 \\
\hline $\begin{array}{l}\text { Flooring and } \\
\text { roofing }\end{array}$ & 12.5 & 8.5 & 12.5 & 12.7 & 11.0 & 12.3 & 12.5 \\
\hline Assets & 5.3 & 2.5 & 8.7 & 9.4 & 4.4 & 9.1 & 7 \\
\hline
\end{tabular}

Source : MPI, 2018

The largest contributors to rural and national povertyare deprivations in years of schooling andnutrition $15.8 \%$ and $15.9 \%$, respectively. In terms ofdimensions, living standards is the largest contributor to multidimensional poverty in rural areas, with acontribution of $44.6 \%$. The dimensions of health andeducation contribute roughly $28 \%$ each.In urban areas, the picture is slightly different. Here,the highest contributor to overall poverty is child mortality,followed by nutrition and years of schooling.The dimension of health contributes $36 \%$ to multidimensionalpoverty in urban areas. In the context of districts, Rautahat is the district with most municipalities in the country, with 16 municipalities out of 18 local units. It is also a district with one of the lowest Human Development Index ratings 0.387 in the country, which is lower than that of several districts in the Karnali such as Jumla, Dolpa and Mugu. According to the MPI report, Mahottari and Sarlahi are the second and third multidimensionally poorest districts, respectively, in the province. On average, the district has a multidimensional poverty index of 47.9, much lesser than the national average of 28.60 . MPI takes into account multiple deprivations at the individual and household level in health, education and standard of living, among others. Hence, the Karnali Province and province no.2 have the highest rate of multidimensional poverty - with every second person being 
multi - dimensionally poor (50\%) - followed by Provinces 5 and 7 (approximately 30\%). The major contributing indicators to overall poverty in Nepal and in rural Nepal are malnutrition and insufficient years of schooling.

\section{Conclusion}

There is more than 28 percent people live in poverty. Women and girls, indigenous and marginal peoples and geographically remote areas peoples are more likely to be poor, despite the significant contribution they make to the economy, especially through unpaid care and household work. More than one-third of Nepal's children less than 5 years are stunted, and 10\% suffer wasting due to acute malnutrition (UNICEF, 2012). Without a concerted effort to tackle inequality and pursue policies that benefit the many rather than the richest few, the poorest and most marginalized people has been continue to be excluded from progress. In the context of provincial level, highest poverty rate is in Province no.2 and lowest level is in Gandaki province which is 35 and 5 percent respectively.

The Multidimensional poverty measures are based on normative decisions about the most important dimensions of poverty and the best indicators for these dimensions, and findings are influenced to a great extent by these judgments. Nepal has been following various methods to measure the poverty in the country. At 2018, Nepal has used the MPI method to measure poverty, having 3 dimensions and 10 indicators, such as nutrition, low education or inadequate sanitation. The latest data adapts the Global MPI to national needs, for example in the case of Nepal to including roofing materials as one of the new indicators of poverty measurement. The global Multidimensional Poverty Index (MPI) is an international measure of acute multidimensional poverty covering over 100 developing countries. It complements traditional monetary-based poverty measures by capturing the acute deprivations that each person faces at the same time with respect to education, health and living standards.

\section{References}

Bakrania, S. (2015). Urban poverty in Nepal. GSDRC Helpdesk Research Report 1322, Birmingham, UK: GSDRC, University of Birmingham.

Chaudhari, M.K. (2018). Economic planning and poverty alleviation strategies in Nepal. Research Nepal journal of development studies, year $1^{\text {st }}$, issue $2^{\text {nd }}, 2018$.

Gorski, P. (2008). The Myth of the Culture of Poverty. Retrieved fromhttp://www.ascd.org/publications/books/116064/chapters/The-Myth-of-the-Culture-ofPoverty.aspx

GNB (2019). Economic and social inclusive corporation. Retrieved fromhttps://www2.gnb.ca/content/gnb/en/departments/esic/overview/content/what_is_poverty .html 
UNDP(2019). Human Development Report 2019. Beyond income, beyond averages, beyond today: Inequalities in human development in the 21st century. New York. Retrieved from http://hdr.undp.org/en/content/human-development-report-2019"

Fox, L (2017). The supplemental poverty measure: 2016.Current Population Reports P60-261 (RV), Revised September 2017.

IRP (2020). How poverty is measured? Retrieved fromhttps://www.irp.wisc.edu/resource/howpoverty-is-measured/, University of Wisconsin, US.

Jenson, E. (2009). Teaching with poverty in mind. Retrieved fromhttp://www.ascd.org/publications/books/109074/chapters/Understanding-the-Nature-of Poverty.aspx.

Kathmandu Post (2020). Rautahat poorest district in Province 2. Retrieved fromhttps://tkpo.st/2S2DA3C,https://kathmandupost.com/province-no-2/2020/02/06/rautahatpoorest-district-in-province-2-policy-commission-says

K.C., N. (2018). Measuring multi-dimensional poverty analysis in Nepal. Research Nepal Journal of Development Studies, 1(2), 62-83. Retrieved fromhttps://doi.org/10.3126/rnjds.v1i2.22427

Lewis Oscar (1969).Culture of poverty. In Moynihan, Daniel P. (ed.). On Understanding Poverty: Perspectives from the Social Sciences. New York: Basic Books.

Maharjan, U. (2019). The 15th plan and implementation. Retrieved from http://therisingnepal.org.np/news/30253

Nikku, B.R\& Azman, A. (2014). Politics, policy and poverty in Nepal. International Journal of Social Work and Human Services Practice, Horizon Research Publishing Vol.2. No.2 Apr, 2014, pp. 1-9. Retrieved fromhttp://www.hrpub.org/download/20140405/IJRH119290002.pdf

NPC (2019). Long term visions of 25 years of Nepal. National Planning Commission, Kathmandu.

Subedi, S.R. (2019). After six decades and billions spent poverty alleviation remains a far cry. Retrieved from https://myrepublica.nagariknetwork.com/news/after-six-decades-and-billionsspent-poverty-alleviation-remains-a-far-cry/

UNICEF (2012). Children's voices : A qualitative study of poverty in Tajikistan. Retrieved fromwww.unicef.org.

World Bank (2016). Commission on global poverty. Retrieved fromhttps://www.worldbank.org/en/programs/commission-on-global-poverty

Worldometer (2019). United Nations, Department of Economic and Social Affairs, Population Division. World Population Prospects: The 2019 Revision. Retrieved from, www.Worldometers.info

$\begin{array}{lllll}\text { Shodhangana } & \text { (2012). } & \text { Poverty. } & \text { Retrieved }\end{array}$ https://shodhganga.inflibnet.ac.in/bitstream/10603/14387/12/12_chapter\%206.pdf 